\title{
Positive Impacts of a University Walking Program: A Case Study
}

\author{
Lisa J. Leininger ${ }^{1, *}$, Kevin D. Dames ${ }^{2}$, Kent J. Adams ${ }^{1}$, Mike Climstein ${ }^{3}$, Mark De Beliso ${ }^{4}$ \\ ${ }^{1}$ Kinesiology Department, California State University Monterey Bay, Seaside, CA, USA \\ ${ }^{2}$ Kinesiology Department, SUNY Cortland, Cortland, NY, USA \\ ${ }^{3}$ School of Health and Human Sciences, Southern Cross University, Gold Coast, Australia; Exercise Health and Performance Faculty \\ Research Group, Faculty of Health Sciences, The University of Sydney, Sydney, New South Wales, Australia \\ ${ }^{4}$ Department of Kinesiology and Outdoor Recreation, Southern Utah University, Cedar City, UT, USA \\ *Corresponding author: lleininger@csumb.edu
}

Received December 01, 2018; Revised January 05, 2019; Accepted January 25, 2019

\begin{abstract}
A sedentary lifestyle is a key contributor to chronic disease, and many occupations in our society are sedentary in nature. Therefore, a main focus of workplace health promotion programs is to increase employee physical activity. In addition, workplaces are an ideal arena to deliver health programming, however many organizations face barriers to implementation, such as staffing, budget and time constraints. The purpose of this case study is to present a real world, cost-effective workplace walking program that positively impacted employee health. Feedback will also be provided on challenges encountered in relation to compliance and retention. Finally, practical, and social applications are discussed.
\end{abstract}

Keywords: workplace health promotion, worksite programs, steps

Cite This Article: Lisa J. Leininger, Kevin D. Dames, Kent J. Adams, Mike Climstein, and Mark De Beliso, "Positive Impacts of a University Walking Program: A Case Study." Journal of Physical Activity Research, vol. 4, no. 1 (2019): 57-61. doi: 10.12691/jpar-4-1-7.

\section{Introduction}

Workplace health promotion programs (WHPPs) have existed for decades, with many documented benefits to both employees and organizations [1-5]. Despite the company and employee benefits, organizations often struggle to incorporate long-term, cost-effective programming into their structure due to budget, staffing, and/or time constraints $[6,7]$.

Many jobs at a university are primarily sedentary, $[8,9]$ and recently there has been a shift in the aim of workplace programming to reduce sedentary behavior throughout the workday $[10,11]$. This practice is supported by recent research promoting the positive effect of reduced sitting time [12]. However, employers may be concerned with this approach, as programming could potentially interfere with work time, work productivity and be costly.

Han et al. [13], recently concluded that future studies on reducing sedentary behavior at the workplace should:

- Be centered around "real world" activities;

- Be used and accepted over extended periods of time;

- Have an impact on markers of fitness and chronic disease risk;

- Improve health outcomes;

- Be cost effective.

In light of these suggestions, the purpose of this case study is to present a real world, cost-effective, annual workplace walking program that has had positive impacts on health-related outcomes. Likewise, we intend to provide feedback with respect to the challenges encountered with regards to participant compliance and retention, along with practical and social applications.

\section{Methods}

\subsection{Design}

The Workplace Walkoff Challenge (WWC) is an annual six-week, pedometer-based walking competition held at a small, public, California State University. The purpose of the WWC is to reduce sedentary behavior while at work, promote physical activity as a regular lifestyle behavior, and improve health outcomes. The competition is open to all employees each spring semester.

\subsection{Participants}

As stated, the most recent WWC was open to all employees at the university $(\mathrm{n}=1,078)$. Of those 1,078 employees, 171 chose to participate in the WWC $(15.9 \%$ participation). In order to highlight the methodology and impact of the WWC, in this description we will focus on the physical activity of 50 individuals who volunteered to be involved in a 12-week research study on physical activity and cardiovascular risk factors that overlapped the WWC. These 50 individuals included those who 
participated in the WWC $(n=33)$ and those who did not participate in the WWC $(n=17)$. The non-participants acted as the control group. Approval to conduct this study was granted by the university's Human Subjects Institutional Review Board and all participants signed an informed consent to participate.

\subsection{Procedures}

The WWC is sponsored by the University Personnel (UP) Department, and administered by a faculty member from the Kinesiology (KIN) Department. This relationship emerged in 2012, when the faculty member was hired, and their professional and research background was in workplace health promotion.

Employees self-assemble into teams of four to eight individuals and register with a team name and photo. Each team member wears a pedometer at all times during the competition (7 days a week) and reports their weekly steps on a website created and maintained by the WWC administration. Pedometers are not provided by the administrators, and employees may elect to use any brand or type they choose. However, those enrolled in any research study are provided an Omron HJ-321 pedometer (Kyoto, Japan) for consistency.

There are several other components to the WWC, including a kick-off event, a series of three "Lunch and Learn" seminars presented by KIN faculty, guided group walks sponsored by a local running store, and an awards ceremony. UP sponsors a light luncheon at the kick-off event, which costs the department approximately $\$ 1500$.

Kinesiology undergraduate students act as Team Advisors. Their responsibilities include sending weekly encouraging emails, acting as primary contacts for their team members, and holding lunch time walks. Students also help with the planning and administration of the program, with tasks such as website and spreadsheet creation, and presenting their teams at the kick-off event.

Prizes are awarded to top team (highest average number of steps per week), top individual (highest step total), most improved (greatest percent increase from week one to six) and others (favorite team name, best team photo, etc.). All prizes are donated from local businesses, with no cost to the university. This is facilitated by the KIN faculty lead that developed relationships with these businesses over the last six years of the WWC. Businesses receive recognition at all events, on the WWC website, and through email announcements.

Each year, the faculty lead conducts a research project that overlaps the WWC. Previous results from studies stemming from the WWC include increased physical activity among WWC participants, reduced perceived stress among female WWC participants compared to those who do not participate [2], and a trend towards a higher self-rated health-related quality of life for those who participate [14].

The purpose of the research project highlighted in this case study was to evaluate physical activity levels and retention between the WWC participants and the control group. The research study included a baseline 2-week period, 6-weeks of the WWC (for participants), and 4 weeks following the WWC. The researchers wished to evaluate if physical activity increased, and if the increase persisted following the WWC for participants.

\subsection{Statistical Analysis}

Descriptive characteristics and average steps per week for the WWC and non-WWC participants are reported graphically. Likewise, the number of participants that adhered to the 12-week study duration are tabulated for both the WWC and non-WWC groups. Data analyses were conducted in MS Excel 2013. The spread sheet was peer reviewed for accuracy as described by Al Tarawneh and Thorne [15].

\section{Results}

Demographics for both the WWC and non-WWC participants are presented in Table 1. Two of the nonWWC participants who enrolled in the study failed to record any walking activity on the research website. As such, the Table 1 data is reflective of 33 participants in the WWC group (female $n=26$ and male $n=7$ ) and 15 in the non-WWC group (female $n=11$ and male $n=4$ ). The BMI was similar between groups: WWC female $=27.6 \pm 6.5$ and male $=27.7 \pm 3.8$, and $\mathrm{WWC}$ female $=28.8 \pm 7.5$ and male $=27.0 \pm 3.4$.

Figure 1 provides a comparison of average steps per week of the WWC and non-WWC participants who completed the 12-week study. The WWC participants recorded greater average steps per week than the nonWWC members for each of the 12-weeks of the study. The difference in average steps per week between the WWC and non-WWC ranged from 6,672 (recorded at week 2) to 17,646 (recorded at week 7).

Table 2 provides the retention of both the WWC and non-WWC groups across the 12-week study period. It should be noted that two participants in the non-WWC group who enrolled in the study did not report any step counts for any week. The non-WWC retention appeared to gradually decline over the 12 -week study. Conversely, the WWC group experienced two abrupt declines in retention following weeks 7 and 11 .

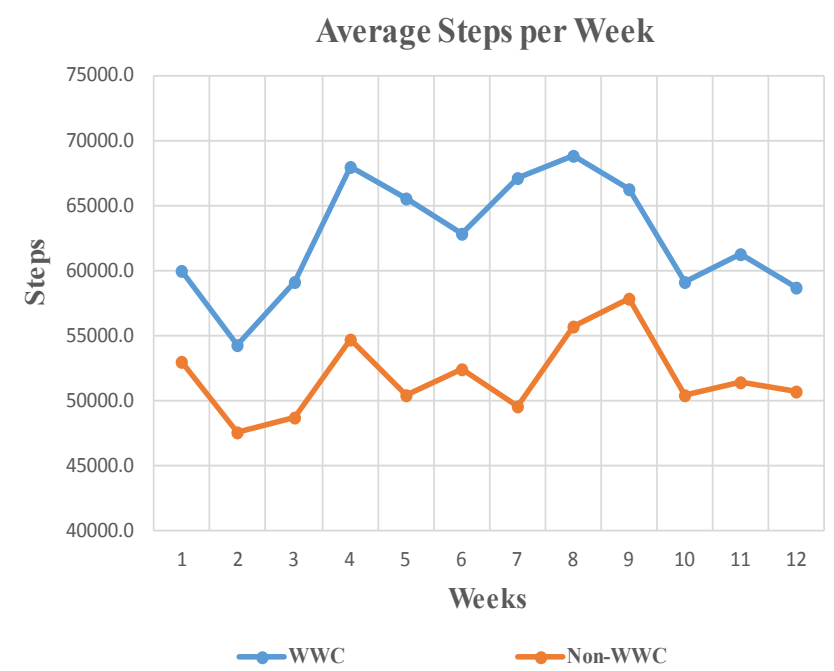

Figure 1. Average steps per week for WWC and non-WWC participants who completed the 12-week study period. 
Table 1. Participant Baseline Descriptive Information

\begin{tabular}{lcccc}
\hline & Age (years) & Height $(\mathrm{cm})$ & Body Mass $(\mathrm{Kg})$ & BMI $\left(\mathrm{Kg} / \mathrm{m}^{2}\right)$ \\
\hline WWC & & & & \\
Female $(\mathrm{n}=26)$ & $41.9 \pm 12.4$ & $165.1 \pm 28.0$ & $75.4 \pm 19.3$ & $27.6 \pm 6.5$ \\
Male $(\mathrm{n}=7)$ & $41.6 \pm 14.3$ & $177.1 \pm 11.1$ & $86.3 \pm 9.9$ & $27.7 \pm 3.8$ \\
Non-WWC & & & & \\
Female (n=11) & $46.8 \pm 13.9$ & $164.4 \pm 6.5$ & $77.4 \pm 18.2$ & $28.8 \pm 7.5$ \\
Male $(\mathrm{n}=4)$ & $40.0 \pm 15.0$ & $188.0 \pm 4.1$ & $95.2 \pm 10.5$ & $27.0 \pm 3.4$ \\
\hline
\end{tabular}

WWC-Workplace Walk-off Challenge. (mean $\pm \mathrm{SD}$ ). BMI-body mass index.

Table 2. Participant Retention

\begin{tabular}{cccccccccccccc}
\hline Week & Pre & 1 & 2 & 3 & 4 & 5 & 6 & 7 & 8 & 9 & 10 & 11 & 12 \\
\hline WWC & 33 & 33 & 32 & 32 & 31 & 31 & 31 & 31 & 28 & 28 & 28 & 28 & 23 \\
Non-WWC & 17 & 15 & 15 & 15 & 14 & 14 & 14 & 13 & 13 & 12 & 12 & 12 & 11 \\
\hline
\end{tabular}

WWC-Workplace Walk-off Challenge.

\section{Discussion}

The intent of this case study was to present a real world, cost-effective, annual workplace walking program that benefits health-related outcomes. Challenges encountered with regards to participant compliance and retention are also highlighted.

The participants who engaged in the study were formally enrolled in the WWC program and an additional sample of workers who wanted to take part in the study for the purpose of recording and monitoring their physical activity as related to steps.

As seen in Table 2, regarding compliance and retention, 28 of the 33 participants who were enrolled in the WWC completed 11 of the 12 weeks of monitoring steps $(\approx 85 \%)$. Following week 11, an additional 5 WWC participants did not report their weekly step counts. We have yet to determine if these participants did not carry out their weekly walking or simply did not report their step counts. We suspect this sudden lack of compliance was related to a campus wide shift in workload corresponding to the end of the semester (as the program ends in late April, with the awards ceremony in early May). The 11 of the 17 initially enrolled non-WWC study participants completed the 12 -week study and reported their weekly step counts ( $\approx 65 \%$ retention/compliance). Based on the aforementioned data, it would appear that the WWC program and incentives were beneficial with regards to retention and compliance of tracking and recording steps.

The weekly step counts for the WWC participants ranged from 54,323 to 68,832 with a 12 -week average of 62,652 . The non-WWC participant's weekly steps ranged from 47,651 to 57,921 with a 12 -week average of 51,926. At no point during the 12-week study did the non-WWC participants complete more steps than the WWC participants. The average difference in weekly steps between the WWC and the non-WWC participants was 10,726. Based on the reported data, it would appear that the WWC program was beneficial in regards to encouraging greater weekly step counts.

There has been a popular notion that a 10,000-step count per day serve as a target metric [16]. Hence, to accomplish such a goal one would need to accumulate 70,000 steps per week. As such, the WWC participant's 12 -week average steps would have been $90 \%$ of the target goal. The non-WWC participant's 12-week average steps achieved only $74 \%$ of the target goal. When considering the steps accumulated during the current study it is important to keep in mind that some researchers [16] consider 10,000 steps per day as a classification of an individual as "active" and that "highly active" is achieved at 12,500 steps per day.

The BMI of the WWC participants averaged $27.7 \pm 3.8$ and $27.6 \pm 6.5 \mathrm{~kg} / \mathrm{m}^{2}$ for men and women respectively. The BMI of the non-WWC participants averaged 27.0 \pm 3.4 and $28.8 \pm 7.5 \mathrm{~kg} / \mathrm{m}^{2}$ for men and women respectively. The BMI of the participants in the current study groups were similar and considered as "overweight" per the strata of BMI 25.0 to $<30.0 \mathrm{~kg} / \mathrm{m}^{2}$ [17]. The participant's BMIs on average were nearly approximate with the 2009-2010 National Health and Nutrition Examination Survey (NHANES) age adjusted mean BMIs of $28.7 \mathrm{~kg} / \mathrm{m}^{2}(95 \%$ CI, $\left.28.3-29.1 \mathrm{~kg} / \mathrm{m}^{2}\right)$ for men and $28.7 \mathrm{~kg} / \mathrm{m}^{2}(95 \% \mathrm{CI}$, $28.4-29.0 \mathrm{~kg} / \mathrm{m}^{2}$ ) for women [18]. It should be noted here that a meta-analysis by Flegal and colleagues [17] reported that individuals categorized as overweight by BMI classification (BMI 25.0 to $<30.0 \mathrm{~kg} / \mathrm{m}^{2}$ ) were associated with a significantly lower all-cause mortality when compared to those categorized as normal weight (BMI 18.5 to $<25 \mathrm{~kg} / \mathrm{m}^{2}$ ).

\subsection{Translational Implications}

In WHPPs, research needs to be tied to practice. With that said, in framing this discussion according to Han et al.'s recommendations [13], there are several research and practical implications of this case study that may help universities and other workplaces implement a program to help reduce sedentary behavior.

Research on the effectiveness of WHPPs should center around "real-world" activities. In this program, walking is the focus of the intervention, and employees receive "tips and tricks" for incorporating more steps throughout the day. These recommendations include getting up every hour from their desk to walk around the office or building, taking walks on breaks, scheduling walking meetings when possible, and scheduling lunchtime walks with co-workers. This type of activity is consistent with the new physical activity recommendations [19], where exercise no longer needs to be completed in any time frame (previously, it was stated that exercise should be in 10-minute bouts). For those individuals who are not 
ambulatory, steps are allowed to be converted from other physical activities. This accommodation is made in order to make the program as inclusive as possible.

Programs should also be used and accepted over time, and having an annual program can help to encourage employees and provide accountability. Further, we found that employees look forward to the WWC, and several teams continue their activity and team walks throughout the year. Several individuals have commented that the annual program is a great "reminder" and "re-motivator" for keeping active throughout the workday, and provides a "check-in" and more accountability. They also state that the team elements and incentives are motivating and provide an element of fun to their physical activity participation.

In addition to the employee benefits, a short-term, annual program may be beneficial for organizations. This university is not unlike others that do not have dedicated staff to administer a WHPP. Therefore, the advantage of a shorter, but regularly occurring program is that they may require less financial input, and may be administered by an employee that has additional job duties besides administering health promotion programs.

Programs should also have an impact on the markers of chronic disease and improve health outcomes, which this program has demonstrated $[2,14]$. Another unique finding was that many participants stated that they volunteered for research projects because it gave them more information about their own health, for free, at a convenient location.

Finally, programs need to be cost-effective for organizations to commit and encourage this type of programming for their employees. As previously stated, this program was conducted by existing employees, with the faculty lead from the Kinesiology Department. This gave the faculty member a unique opportunity to work on retention, tenure and promotion, and incorporate undergraduates into experiential learning and research. All prizes were donated from on-campus departments and local organizations. UP did provide one lunch at the kick-off event, which could be omitted if funds are not available. All students were volunteers, and all WWC participants provided their own pedometers. Therefore, this program was successfully conducted with less than $\$ 2000.00$, and as stated previously, that cost could be further reduced if necessary.

\subsection{Social Implications}

After several years of the WWC, the administrators have realized that there are many social implications for a WHPP of this design. First, at a university, departments and colleges are often "siloed" and faculty and staff across campus often have little contact. A program such as the WWC brings together faculty, staff, administrators, and departments together in a fun, supportive atmosphere. Additionally, the team members are often from similar departments, and thus, this activity has the potential to be a great team-building activity and increase camaraderie within offices.

The interaction of students with staff and administration was also an unforeseen benefit. Personnel that are routinely behind the scenes at a university, having little contact with students, were elated about their positive interaction with Kinesiology students, and vice versa. Staff informed us it "gave them a sense of purpose". Students also appreciated the interaction, stating that it gave them a sense of "connection". Overall, the potential benefit helping to create a sense of community and belonging cannot be overlooked. Overall, the goodwill from naturally occurring relationship building had benefits across campus at all levels from students to administration.

\section{Conclusion}

The WWC provides a unique opportunity for universities to offer regular health promotion programming that can improve health indicators in a cost-effective manner. Additionally, the WWC provides opportunities for experiential learning for students, while involving them in the research process, and connecting them with behind the scenes university staff and administration. We believe all of these benefits to the student may lead to increased engagement at the university, enrichment of their overall academic program, along with the ability to increase student success. The WWC also provides opportunities for research to be conducted, and the faculty members involved to work on their scholarship.

Within the parameters of this study, it was determined that a walking challenge can be an efficient, practical way to increase employee's physical activity which has a positive benefit on health. Second, a walking challenge can have positive effects on employee morale, relationships and communication.

\section{References}

[1] Leininger, L.J., Harris, D., Tracz, S., and Marshall, J.E., "Differences in physical activity participation between university employees with and without a worksite health promotion program", Californian Journal of Health Promotion, 11(1). 67-75. 2013.

[2] Leininger, L.J., Orozco, B.Z., and Adams K.J., "Worksite based walking competition: effects on perceived stress and physical activity in female university employees", Journal of Fitness Research, 3(1). 32-38. April 2014.

[3] Fonarow, G.C., Calitz, C., Arena, R., Baase, C., Isaac, F.W., Lloyd-Jones, D., Peterson, E.D., Pronk, N., Sanchez, E., Terry, P.E., Volpp, K.G., and Antman, E.M.; on behalf of the American Heart Association. "Workplace wellness recognition for optimizing workplace health: a presidential advisory from the American Heart Association", Circulation, 131. e480-e497. May 2015.

[4] Goetzel, R.Z., Henke, R.M., Head, M.A., Benevent, R., and Calitz, C., "Workplace programs, policies, and environmental supports to prevent cardiovascular disease", Health Affairs, 36(2). 229-236. February 2017.

[5] Lowensteyn, I., Berberian, V., Belisle, P., DaCosta, D., Joseph, L., and Grover, S.A., "The measurable benefits of a workplace wellness program in Canada", Journal of Occupational and Environmental Medicine, 60(3). 211-216. March 2018.

[6] Hannon, P.A., Garson, G., Harris, J., Hammerback, K., Sopher, C., and Clegg-Thorp, C., "Workplace health promotion implementation, readiness, and capacity among mid-size employers in low-wage industries: a national survey", Journal of Occupational and Environmental Medicine, 54(11). 1337-1343. November 2012.

[7] McCoy, K., Stinson, K., Scott, K., Tenney, L., and Newman, L., "Health promotion in small business: a systematic review of factors influencing adoption and effectiveness of worksite wellness programs", Journal of Occupational and Environmental Medicine, 56(6). 579-587. June 2014. 
[8] Bureau of Labor Statistics, U.S. Department of Labor, "Standing or walking versus sitting on the job in 2016", The Economics Daily, Retrieved: https://www.bls.gov/opub/ted/2017/standing-orwalking-versus-sitting-on-the-job-in-2016.htm. January 2019.

[9] Church, T.S., Thomas, D.M., Tudor-Locke, C., Katzmarzyk, P.T., Earnest, C.P., et al. "Trends over 5 decades in U.S. occupationrelated physical activity and their associations with obesity. PLoS ONE 6(5). May 2011.

[10] Chu, A.H.Y., Ng, S.H.X., Tan, C.S., Win, A.M., Koh, D., and Muller-Reimenschneider, F., "A systematic review and metaanalysis of workplace intervention strategies to reduce sedentary time in white-collar workers", Obesity Reviews, 17(5). 467-481. March 2016.

[11] Healy, G.N., and Goode, A.D., Sedentary Behavior Epidemiology, Springer, New York, 2018, 455-457.

[12] Diaz, K.M., Duran, A.T., Colabianchi, N. Judd, S.E., Howard, V.J. and Hooker, S.P., "Potential effects on mortality of replacing sedentary time with short sedentary bouts or physical activity: a national cohort study", American Journal of Epidemiology, kwy271.

[13] Han, H., Lim, J., Vishkochil, R., Aguiar, R., Elroy, J., TudorLocke, C., and Chipkin, S.R., "Pilot study of impact of a pedal desk on postprandial responses in sedentary workers", Medicine \& Science in Sport \& Exercise, 50(10). 2156-2163. June 2018.
[14] Orozco, B.Z., Leininger, L.J., and Contente, K., "Effect of a worksite walking competition on health-related quality of life among university employees", American Journal of Undergraduate Research, 12(3). 37-44. May 2015.

[15] Al Tarawneh, G., and Thorne, S., "A pilot study exploring spreadsheet risk in scientific research", in Proceedings of the EuSpRG 2016 conference. 49-69. March 2017.

[16] Locke, C. T., and Basset, D. R., "How many steps/day are enough: preliminary pedometer indices for public health", Sports Medicine, 34(1). 1-8. 2004.

[17] Flegal, K.M., Kit, B.K., Orpana, H., and Graubard, B.I., "Association of all-cause mortality with overweight and obesity using standard body mass index categories: a systematic review and meta-analysis", Journal of the American Medical Association, 309(1). 71-82. January 2013.

[18] Flegal, K., Caroll, M., Ogden, C., and Curtin, L., "Prevalence and trends in obesity among US adults, 1999-2008", Journal of the American Medical Association, 303(3), 235-241. January 2010.

[19] United States Department of Health and Human Services., "Physical activity guidelines, 2nd edition 2018", Retrieved from: https://health.gov/paguidelines/secondedition/pdf/Physical_Activity_Guidelines_2nd_edition.pdf. January 2019

(C) The Author(s) 2019. This article is an open access article distributed under the terms and conditions of the Creative Commons Attribution (CC BY) license (http://creativecommons.org/licenses/by/4.0/). 